\title{
A corner store intervention in a low-income urban community is associated with increased availability and sales of some healthy foods
}

\author{
Hee-Jung Song ${ }^{1, *}$, Joel Gittelsohn ${ }^{1}$, Miyong Kim ${ }^{2}$, Sonali Suratkar ${ }^{1}$, Sangita Sharma ${ }^{3}$ \\ and Jean Anliker ${ }^{4}$ \\ ${ }^{1}$ Center for Human Nutrition, Department of International Health, Bloomberg School of Public Health, Johns \\ Hopkins University, 615 N. Wolfe Street, Baltimore, MD 21205-2179, USA: ${ }^{2}$ Department of Community and \\ Public Health, School of Nursing, Johns Hopkins University, 525 N. Wolfe Street, Baltimore, MD 21205-2179, \\ USA: ${ }^{3}$ Nutrition Research Institute, University of North Carolina at Chapel Hill, 500 Laureate Way, Rm\# 1102 , \\ Kannapolis, NC 28081, USA: ${ }^{4}$ Department of Nutrition, University of Massachusetts, 206A Chenweth Lab, \\ 100 Holdsworth Way, Amherst, MA 01003-9282, USA
}

Submitted 12 August 2008: Accepted 21 January 2009: First published online 30 April 2009

\begin{abstract}
Objective: While corner store-based nutrition interventions have emerged as a potential strategy to increase healthy food availability in low-income communities, few evaluation studies exist. We present the results of a trial in Baltimore City to increase the availability and sales of healthier food options in local stores. Design: Quasi-experimental study.

Setting: Corner stores owned by Korean-Americans and supermarkets located in East and West Baltimore.

Subjects: Seven corner stores and two supermarkets in East Baltimore received a 10-month intervention and six corner stores and two supermarkets in West Baltimore served as comparison.

Results: During and post-intervention, stocking of healthy foods and weekly reported sales of some promoted foods increased significantly in intervention stores compared with comparison stores. Also, intervention storeowners showed significantly higher self-efficacy for stocking some healthy foods in comparison to West Baltimore storeowners.

Conclusions: Findings of the study demonstrated that increases in the stocking and promotion of healthy foods can result in increased sales. Working in small corner stores may be a feasible means of improving the availability of healthy foods and their sales in a low-income urban community.
\end{abstract}

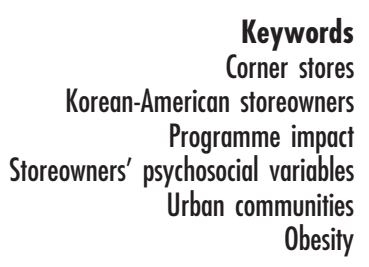

The obesogenic environment, characterized by abundant energy-dense foods, larger portion sizes and less availability of healthy foods, particularly affects poor ethnic minority populations in urban communities ${ }^{(1-5)}$. Low-income urban communities are less likely to have access to healthier foods at affordable prices due to supermarket migration to suburbs and the scarcity of healthy foods at small neighbourhood stores ${ }^{(6-11)}$. Nutrition interventions aiming to improve the availability of healthy foods in urban communities have been suggested as a promising and sustainable strategy to improve nutrition environments of communities and to address diet-related chronic diseases ${ }^{(12-16)}$. Corner stores have unique potential to improve the nutrition environment due to their high prevalence in low-income urban settings.

Previous food store-based interventions have been implemented mostly in supermarkets and shown modest success $^{(17)}$. Corner store-based programmes are in their infancy and little is known about the feasibility of such interventions. One descriptive study in California showed that small neighbourhood food retailers could feasibly fulfil the needs of their Latino customers to ensure food security of community residents ${ }^{(18)}$. Other corner store-based nutrition programmes supported by city agencies and non-profit organizations have had success in low-income urban communities by significantly increasing the variety and sales of produce ${ }^{(9)}$. Unfortunately, to our knowledge, all previous corner store-based nutrition interventions have been single case studies which lacked comparison groups and the programme results have not been formally evaluated ${ }^{(9,18,19)}$. Systematic studies of corner store-based nutrition interventions which report change in promoted food stocking and 
sales, and storeowners' psychosocial variables, have not been reported.

Baltimore Healthy Stores (BHS) is a food store-based nutrition intervention to improve the availability of healthy foods in Baltimore City. In combination with pointof-purchase promotions, the programme aims to increase the purchasing and consumption of healthy foods by customers. The first round of the BHS programme was conducted to assess the feasibility of the intervention by observing its impact on stocking and sales of healthy foods. We view feasibility as comprising three main components: acceptability, operationality and sustainability. Acceptability refers to cultural and economic acceptability for customers and willingness to accept intervention strategies by storeowners. Operationality indicates that the storeowners actually make the changes that are needed, such as stocking healthier food options. Sustainability is defined as the likelihood that storeowners will sustain the programme beyond the completion of intervention. From our perspective, the sustainability of the programme can be predicted and assessed by the promoted food sales.

The purpose of the current paper is to present the results of the feasibility trial of a corner store intervention in a low-income urban community. Key questions addressed are:

1. How acceptable was the programme to storeowners? What was the impact of the programme on storeowners' psychosocial factors?

2. How operational was the BHS programme? Did intervention storeowners make operational changes by stocking promoted foods at increased rates?

3. How sustainable was the programme? Did sales of promoted foods in intervention stores increase postintervention?

\section{Methods}

\section{Study setting and design}

The first round of the BHS programme took place in East and West Baltimore, two of the poorest areas in Baltimore City. The median household income by neighbourhood in 2000 was about \$US $17000-18000$ compared with \$US 30000 in Baltimore City. About $85-90 \%$ of East and West Baltimore's population is African-American (www.baltometro.org). In Baltimore City, the estimated number of Korean-American merchants ranges from 1000 to $2000^{(20)}$. Of these, about 750 Korean-American merchants are Korean-American Grocers Association (KAGRO) members and about $70 \%$ of KAGRO members are engaged in grocery stores or food service areas. We estimate that $75 \%$ of all small food stores in Baltimore City are owned and operated by Korean-Americans.

The study had a quasi-experimental design where a sample of stores in East Baltimore received the intervention and stores in West Baltimore served as comparisons.
Small stores were recruited by first establishing a collaborative relationship with the KAGRO chapter in Baltimore City. KAGRO provided a letter of support that was distributed to corner stores in East and West Baltimore areas, along with programme materials and FAQ (frequently asked questions) sheets. Next, the first author met with small storeowners and provided further explanation. A total of seventeen stores (four supermarkets and thirteen Korean corner stores) agreed to participate in the programme. Since this was a feasibility trial with limited resources and time frame, the number of stores included in the study was limited to eight to ten in each area. A local supermarket chain that services the East and West Baltimore areas was contacted and recruited for participation by the second author. Nine stores (two supermarkets, seven corner stores) in East Baltimore served as intervention stores, and eight stores (two supermarkets, six corner stores) in West Baltimore were used for comparison.

\section{Intervention strategies}

From January to October 2006, we implemented the intervention in nine food stores in East Baltimore. The BHS intervention consisted of five themed phases wherein different healthy foods were promoted at the point of purchase. Each intervention phase was conducted for two months.

Ten healthy foods were promoted. The selection of these foods was based on extensive $24 \mathrm{~h}$ recalls from the community to identify target foods which contributed most energy, fat and sugar intakes ${ }^{(21)}$. The promoted healthy foods selected were clearly defined based on standard criteria and consistent with general standard dietary guidelines. For example, low-sugar or high-fibre cereals were defined as cereals with less than 10 grams of sugar per serving or more than $10 \%$ of the daily value for fibre per serving, respectively. Healthier alternatives were selected that cost the same or less than the less healthy foods they were intended to replace.

The storeowners were requested to stock the promoted foods and display in-store intervention materials for customers. The intervention strategies for corner stores included four main components.

1. Small monetary incentives ( $\$$ US $25-50$ ) were given to stores per intervention phase to cover initial stocking costs.

2. Cultural guidelines were developed to assist storeowners build better relationships with community members by recognizing points of frictions that often arise from cultural misunderstanding between KoreanAmerican storeowners and customers. Twelve practical suggestions including 'Contribute part of your profits back to the community and advertise it' and 'Make eye-contact and small talk' were based on extensive formative research in the community (reference 16; HJ Song, J Gittelsohn, J Anliker, S Suratkar, 
S Sharma and MT Kim, unpublished results) and listed on a Korean-language laminated poster.

3. Nutrition education training/booklet: To ensure longer sustainability of the programme by improving nutrition-related knowledge of corner storeowners, a 45 to 60 min nutrition education session was developed and delivered to the storeowners in Korean by a Korean doctoral student.

4. Corner store guidelines provided strategic guidance with regard to food purchasing, stocking and placing. These were practical suggestions about which types of foods the storeowners should buy, stock and promote; and where storeowners could display such foods for easy access.

Additional strategies were developed to appeal to local consumers. These included in-store intervention materials (posters, educational displays, flyers and shelf labels) and in-store promotions such as taste tests, incentives and giveaways $^{(22)}$.

\section{Data collection instruments}

Data collection instruments included: (i) a Store Impact Questionnaire (SIQ); (ii) weekly food sales records; and (iii) unstructured interviews. Implemented at baseline and post-intervention, the SIQ was a primary store evaluation instrument which recorded physical store characteristics and storeowners' psychosocial factors including food-related knowledge, self-efficacy for healthy food stocking, outcome expectations for food sales and programme effect. Weekly food sales records were developed and used only for the corner stores to assess the promoted food stocking and sales of key promoted foods. Most small storeowners do not keep accurate records of sales, and those who do consider the information to be highly confidential. Owing to these issues, we developed the weekly food sales record to collect reported unit sales of the promoted healthy foods, which was acceptable to collect from these small storeowners and was within their ability to estimate. The programme staff visited the corner stores at baseline, before and after each food's intervention phase and post-intervention to collect the weekly food sales records. These records included the list of all ten promoted foods. Assessment of the stocking and sales of foods was based on storeowner recall, as records were not kept in small stores. For each type of promoted healthy foods, the storeowners were asked whether they stocked the food, how the amount of healthy foods stocked changed and how many units of the promoted food were sold during the last $7 \mathrm{~d}$. The weekly food sales records were not obtained in the supermarkets since assessing the stocking and sales feasibility at corner stores was the major aim of this trial.

Unstructured interviews provided additional information on the storeowners' perspectives and the operation of corner stores. All data were collected by the first author and interviews with corner storeowners were conducted in Korean. A detailed description of study setting, store recruitment, data collection instruments for customers and a presentation of the impact of the programme on local consumers are given elsewhere (reference 22; J Gittelsohn, HJ Song, S Suratkar, M Kumar, E Gronewold, S Sharma, M Mattingly, J Alexander and J Anliker, unpublished results).

\section{Data analysis}

A series of psychosocial scores were developed to assess the main psychosocial variables of storeowners/managers. All scales were assessed for internal reliability. Outcome expectations of food sales summed scores for twenty-three healthy promoted foods. Using a 5-point Likert scale of 'strongly agree' to 'strongly disagree', storeowners specified their level of agreement with such statements as ' $1 \%$ or skimmed milk will sell well in my store'. Scale scores ranged from 23 to 115 , with a mean of $73 \cdot 3(\mathrm{SD}=14 \cdot 2$, $\alpha=0 \cdot 89$ ). Outcome expectations of BHS promotion effect summed scores for five items. Using a 5-point Likert scale, storeowners were asked how much they agreed with statements related to the BHS promotion effect on sales. Scale scores ranged from 5 to 25 , with a mean of $15 \cdot 6$ ( $\mathrm{SD}=4 \cdot 7, \alpha=0 \cdot 82$ ). Self-efficacy was based on twentythree statements about healthy food stocking. Scale scores ranged from 23 to 115 with a mean of $84 \cdot 8$ ( $\mathrm{SD}=14 \cdot 6$, $\alpha=0 \cdot 75$ ). Food knowledge was calculated by adding scores for correct answers to nine questions on healthy food choices and interpretation of a food label. Scores ranged from 0 to 9 , with a mean of $5 \cdot 8(\mathrm{SD}=2 \cdot 1, \alpha=0 \cdot 70)$.

Each store received a stocking score. This was created by adding one point for each type of promoted food in stock at baseline, post-phase and post-intervention, respectively. The ten types of promoted foods were: lowsugar cereal; high-fibre cereal; low-fat milk; cooking spray; baked/low-fat chips; low-salt crackers; fresh fruits; whole wheat breads; diet beverages; and 100\% fruit juice. The stocking scores for each corner store ranged from 0 to 10 points each at baseline, post-phase and postintervention. The stocking score was created to assess only the feasibility of stocking types of healthy foods at corner stores, not to evaluate the magnitude or spectrum of healthy foods being stocked. Using the stocking score, the stocking feasibility between intervention and comparison stores was compared while minimizing the variability of healthy foods stocking among stores.

A sales score was calculated by adding one point for each type of promoted healthy food if at least one unit was sold at baseline, post-phase and post-intervention. The sales scores for each corner store ranged from 0 to 10 at baseline, post-phase and post-intervention, respectively. Like the stocking score, the sale score was created to assess only the feasibility of sales of types of healthy foods at corner stores, not to capture the variability of the number of units sold. 
Average stocking and sales scores of intervention and comparison stores at baseline, post-phase and postintervention were compared to assess the feasibility of healthy food stocking and sales at corner stores.

An overall healthy food stocking and sales (HFSS) score was calculated to show the change in food stocking and sales for each store. From 0 to 2 points were assigned to each promoted food, based on its stocking and sales at baseline and post-intervention. The highest score, 2, was given to a promoted healthy food when the food was available at post-intervention and sales of the promoted food increased from baseline to post-intervention. The HFSS is a comprehensive score which is less susceptible to outliers and captures a wider range of variation of promoted food sales at corner stores while considering the food stocking.

Within-group comparisons for paired observations in intervention and control stores were conducted using Wilcoxon signed rank tests. Wilcoxon rank sum tests were used to compare the study results between intervention and comparison stores.

The study was approved by the Johns Hopkins Bloomberg School of Public Health Committee on Human Research, and informed consent was obtained from all respondents.

\section{Results}

\section{Change in corner storeowners' psychosocial variables}

Overall, there were no statistically significant changes from baseline to post-intervention in scales created to assess storeowners' outcome expectations for healthy food sales or programme effects, self-efficacy or knowledge scores between intervention and comparison corner stores (Table 1). However, significant changes were observed for some specific foods. Outcome expectations for low-salt cracker sales decreased significantly in comparison stores. Intervention storeowners tended to increase outcome expectations for the effectiveness of taste tests $(P=0 \cdot 06)$. Self-efficacy scores for stocking promoted healthy foods such as low-sugar cereals and low-fat salad dressing increased significantly in intervention stores, but decreased in comparison stores. Knowledge scores increased slightly in intervention corner storeowners but decreased in comparison corner storeowners, although the difference was not statistically significant.

\section{Psychosocial variables comparing corner storeowners and supermarket managers}

Corner storeowners' psychosocial variables were compared with those of supermarket managers to examine differences and to see how psychosocial factors of two different types of storeowners/managers affect healthy food stocking and sales. There were no statistically significant differences

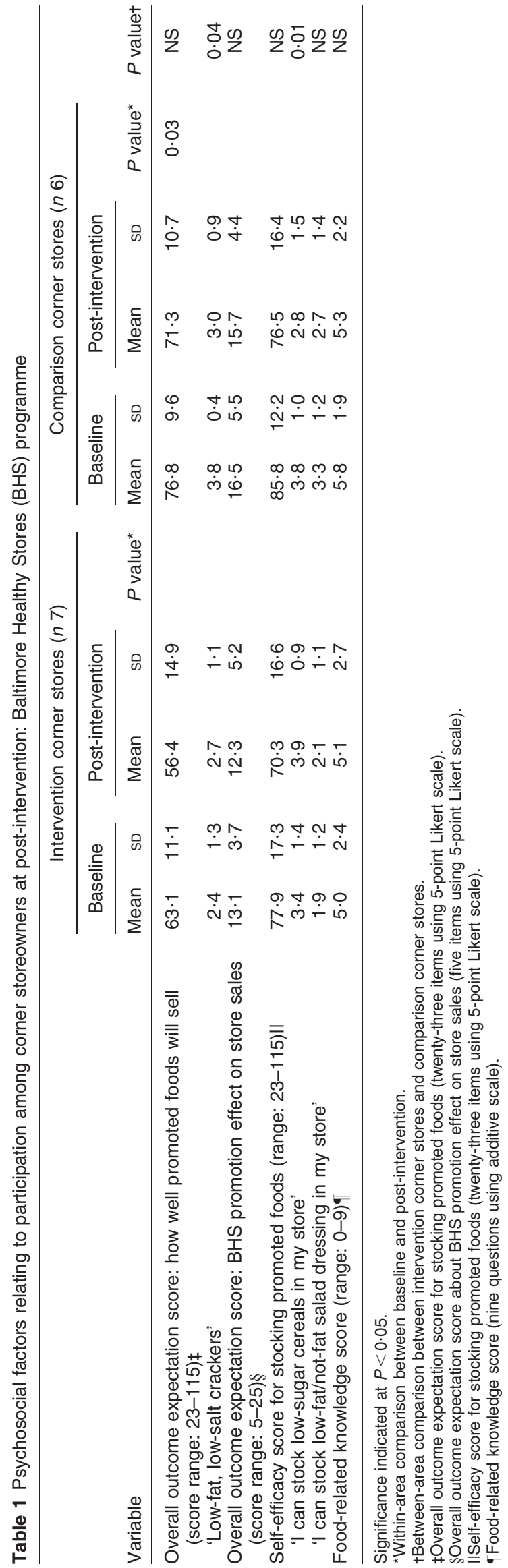


Table 2 Average stocking and sales scores ${ }^{\star}$ at baseline, post-phase and post-intervention for intervention corner stores $(n 7) v$. comparison corner stores $(n 6)$ : Baltimore Healthy Stores (BHS) programme

\begin{tabular}{|c|c|c|c|c|c|c|c|c|c|c|}
\hline & \multicolumn{5}{|c|}{ Average stocking score (range: $0-10$ ) } & \multicolumn{5}{|c|}{ Average sales score (range: $0-10$ ) } \\
\hline & \multicolumn{2}{|c|}{ Intervention } & \multicolumn{2}{|c|}{ Comparison } & \multirow[b]{2}{*}{$P$ value } & \multicolumn{2}{|c|}{ Intervention } & \multicolumn{2}{|c|}{ Comparison } & \multirow[b]{2}{*}{$P$ value } \\
\hline & Mean & SD & Mean & SD & & Mean & SD & Mean & SD & \\
\hline Baseline & $5 \cdot 9$ & $2 \cdot 0$ & $6 \cdot 8$ & $1 \cdot 6$ & NS & $4 \cdot 4$ & $1 \cdot 8$ & $5 \cdot 0$ & 1.5 & NS \\
\hline Post-phase & $8 \cdot 3$ & $1 \cdot 0$ & $6 \cdot 0$ & $1 \cdot 8$ & 0.004 & $7 \cdot 1$ & $2 \cdot 0$ & $5 \cdot 8$ & $1 \cdot 8$ & 0.05 \\
\hline Post-intervention & $7 \cdot 0$ & $2 \cdot 0$ & $5 \cdot 5$ & $1 \cdot 5$ & 0.009 & $6 \cdot 4$ & $1 \cdot 8$ & $4 \cdot 7$ & 1.5 & 0.003 \\
\hline
\end{tabular}

Significance indicated at $P<0.05$.

*The stocking and sales score was created by adding one point for each type of promoted healthy foods stocked (or sold) in corner stores The mean of stocking and sales scores of each promoted healthy food items ranges from 0 (no stores in each area stock a promoted healthy food) to 1 (all of the stores in the area stocks the promoted healthy food). Therefore, the average stocking or sales scores of ten promoted healthy foods range from 0 to 10 .

in psychosocial variables from baseline to post-intervention between supermarket managers and corner storeowners, but supermarket managers had much higher scores for outcome expectations for healthy food sales, the programme effects and self-efficacy for stocking healthy foods at both baseline and post-intervention.

\section{Changes in stocking of promoted foods}

Since supermarkets already stock a variety of the promoted healthy foods, changes in stocking of promoted foods were not assessed. For each type of promoted healthy food, the changes between the percentage of corner stores stocking it at baseline and the percentage at postintervention were compared. While corner stores in the comparison area had no or little change, significantly more corner stores in the intervention area showed increased stocking of some healthy foods at post-intervention. This was true for low-sugar cereals, baked/low-fat chips, lowsalt crackers and cooking spray. For example, from baseline to post-intervention, the percentage of intervention corner stores stocking cooking spray increased by about $71 \%$ while the percentage of comparison corner stores stocking it decreased by about $50 \%$, a significant reduction. Average stocking scores were significantly greater at postphase and post-intervention in intervention stores than in comparison stores (Table 2).

We also assessed the promoted healthy foods stocking at a follow-up six months after the programme for intervention stores only, to ensure the sustainability. The stocking of baked/low-fat chips, low-salt crackers, cooking spray and whole wheat breads was sustained well even six months after the programme.

\section{Changes in sales of promoted food at corner stores}

Table 3 presents average weekly sales of promoted foods at baseline and post-intervention between intervention and comparison stores. Weekly sales of low-sugar cereals, cooking spray, baked/low-fat chips, low-salt crackers, whole wheat bread and $100 \%$ fruit juices increased from baseline to post-intervention in intervention stores while
Table 3 Weekly sales of promoted foods at baseline and postintervention for intervention corner stores $(n$ 7) $v$. comparison corner stores ( $n$ 6): Baltimore Healthy Stores (BHS) programme

\begin{tabular}{|c|c|c|c|c|c|}
\hline \multirow[b]{3}{*}{ Promoted food } & \multicolumn{4}{|c|}{ Unit sale difference* } & \multirow[b]{3}{*}{$P$ value } \\
\hline & \multicolumn{2}{|c|}{ Intervention } & \multicolumn{2}{|c|}{ Comparison } & \\
\hline & Mean & SD & Mean & SD & \\
\hline Low-sugar cereals (box) & $3 \cdot 9$ & $8 \cdot 8$ & $-1 \cdot 9$ & $1 \cdot 4$ & $0 \cdot 13$ \\
\hline High-fibre cereals (box) & -0.8 & $2 \cdot 1$ & $-2 \cdot 8$ & $2 \cdot 6$ & $0 \cdot 20$ \\
\hline Low-fat milk (gallon) & -0.4 & $1 \cdot 3$ & -1.9 & $2 \cdot 7$ & $0 \cdot 23$ \\
\hline Cooking spray (can) & $0 \cdot 3$ & 0.5 & -0.5 & 0.6 & 0.05 \\
\hline Baked/low-fat chips (bag) & $1 \cdot 1$ & $2 \cdot 0$ & 0 & 0 & $0 \cdot 13$ \\
\hline Low-salt crackers (bag) & $0 \cdot 3$ & $0 \cdot 8$ & $-0 \cdot 4$ & $0 \cdot 7$ & $0 \cdot 13$ \\
\hline Whole wheat bread (loaf) & $0 \cdot 4$ & $6 \cdot 2$ & -1.9 & $8 \cdot 3$ & $0 \cdot 71$ \\
\hline Diet soda/diet drinks & $-10 \cdot 0$ & $39 \cdot 2$ & $10 \cdot 5$ & $29 \cdot 5$ & 0.58 \\
\hline $100 \%$ fruit juice (bottle) & $4 \cdot 9$ & $39 \cdot 4$ & $-10 \cdot 6$ & $59 \cdot 8$ & 0.63 \\
\hline Water (bottle) & $-15 \cdot 8$ & $91 \cdot 9$ & $-2 \cdot 2$ & $56 \cdot 5$ & $0 \cdot 83$ \\
\hline
\end{tabular}

Significance indicated at $P<0.05$.

${ }^{*}$ Actual number of units sold was collected using the weekly food sales records and assessment of sales of promoted food was based on storeowners' recall.

decreasing in comparison stores. In particular, the increase in weekly sales of cooking spray was statistically significant for intervention stores. The average sales scores for all promoted foods combined were significantly higher for intervention than control stores at both post-phase and post-intervention, suggesting the intervention stores were more likely to sell the promoted healthy foods at these points in time (Table 2).

When we examined trends in weekly promoted food sales at baseline, pre- and post-phase (right before and after each intervention phase) and post-intervention, the promoted food sales for intervention corner stores tended to reach their height at post-phase, falling off slightly at post-intervention; for comparison stores, sales decreased consistently. Mean HFSS score for intervention and comparison stores was $10 \cdot 3(\mathrm{SD}=3 \cdot 3)$ and $6 \cdot 8(\mathrm{SD}=$ $2 \cdot 4)$ respectively, with the difference in mean scores approaching statistical significance $(P=0 \cdot 06)$. This suggests that promoted healthy foods were both stocked and sold more often in intervention stores following promotional activities. 


\section{Discussion}

The present innovative, 10-month trial supports the potential of urban corner stores as a feasible and sustainable venue for improving the community food environment.

Programme impact on increasing healthy foods availability and sales was modest, but positive. In intervention stores, the stocking of some promoted healthy foods improved and was well sustained even six months after the programme was completed. Although the present study focused on increasing the stocking of healthy foods at corner stores, increasing the allocation of shelf space to healthy foods is another approach that should be tried in future studies, since this has been associated with increased consumption of such foods among community residents ${ }^{(23)}$. Furthermore, we feel that corner store-based interventions need to first focus on assessing the feasibility of healthy foods stocking and sales before different varieties of healthy foods can be addressed, since stocking and selling healthy foods itself is the major issue. Increasing the availability of different types of healthy foods in each food category is the next step to consider.

In our study, when sales patterns were compared with stocking, weekly sales of promoted foods increased in intervention stores, corresponding to the stocking of those foods. When the stocking of some promoted foods such as high-fibre cereals and low-fat milk did not improve, there was also no improvement in sales of those foods.

Promoted healthy foods vary in their acceptability to corner storeowners (in terms of stocking) and to customers (in terms of purchasing). Some foods were more acceptable to both corner storeowners and customers than others within the same category. For example, the message of the first intervention phase was 'healthy breakfast' and the promoted foods were low-sugar and/ or high-fibre cereals. Although the storeowners were recommended to stock both low-sugar and high-fibre cereals, the storeowners increased only the stocking of low-sugar cereals. The rationale by storeowners was that they increased the stocking of low-sugar cereals because customers preferred it over high-fibre cereals ${ }^{(21)}$. These preferred foods can be used as 'initial foods' at the beginning of the intervention to encourage storeowners to stock healthier foods. Increasing the availability of the initial foods is critical for success of corner store-based interventions because these initial foods are more acceptable to customers and acceptance of those foods by the community will lead to better sales which motivate corner storeowners to try and stock other healthy foods. Furthermore, even small increases in the sales and stocking of healthy foods at corners stores suggest great potential of corner store-based programmes since, unlike supermarkets, corner stores and the neighbouring community can quickly respond to small changes of each other. If corner storeowners stock a few items and sell them regularly, they are likely to continue stocking those items because they are very responsive to communities' demand.

Previous store-based interventions have shown that customers' purchasing behaviours are more likely to improve for programmes lasting longer (more than 2 years) ${ }^{(24-26)}$. Since the current study lasted only 10 months, it is possible that a longer trial would result in more statistically significant programme impacts on promoted food sales and storeowners' psychosocial variables.

Overall, the impacts of the BHS programme on storeowner psychosocial factors were small. Decreases in selfefficacy for stocking some of the promoted foods appeared to be related to seasonality or storeowners' perceived barriers to stocking these foods. For example, storeowners consistently referred to high-fibre cereals as one of the least popular foods due to low customer demand. These findings are consistent with those of Skerratt ${ }^{(27)}$, who found that unpredictable purchasing patterns of the community reduced food providers' confidence in supplying particular foods, resulting in decreased self-efficacy for stocking those foods. In addition, corner storeowners often met challenges in acquiring promoted foods. Although the storeowners could order new foods from vendors, most did not want to change their routine ordering procedures due to language barriers, concerns about low customer demand, or the financial burden of purchasing goods in bulk. In spite of monetary incentives given to intervention stores to cover financial risk, the storeowners were still reluctant to purchase new foods and felt bad about unsold items. Future corner store-based nutrition interventions in urban communities should take into account various aspects such as corner storeowners' perceived barriers and structural problems related to food stocking and ordering procedure.

In the present study, supermarkets were included only for the analysis of psychosocial variables. Stocking healthy foods was not a major issue at supermarkets compared with corner stores since supermarkets already stocked a wide variety of healthy foods. Also, the promoted food sales were reported only for corner stores because participating supermarkets later proved reluctant to release their sales data.

The study had several limitations. Due to lack of a computerized sales tracking system at corner stores, promoted food sales were determined from storeowners' recalls using weekly food sales records. Total store sales or comparative food sales were not collected because these caused too much subject burden on the storeowners. While the possibility of secular changes is of concern, our use of a set of comparison stores where stocking and sales did not increase ameliorates this concern. An increase in stocking or promoted foods sales only in intervention area stores is very unlikely considering the comparable characteristics of the two study areas.

Also, the costs of the foods were not assessed in our study. However, when we selected the promoted healthy foods for the programme, we made sure the 
foods were comparable in cost to the same type of less healthy foods.

Another possibility regarding the increased promoted food sales in intervention stores is that intervention corner storeowners may have sold the promoted healthy foods at a loss. However, the storeowners said that they rarely sell items at a loss because it results in a lot of complaints from customers when the sale is over. Another main challenge was the high turnover of store managers and corner storeowners. After collecting baseline data, some corner stores closed or changed ownership, forcing us to recollect baseline data or recruit additional stores.

In spite of these limitations, the findings of the present study provide important implications for future corner store-based nutrition interventions in urban communities. We were able to increase stocking and sales of some healthy foods in urban corner stores, and these changes were sustained six months post-intervention. Corner store and other small store interventions may be a viable means of improving access to healthy foods in poor urban settings.

\section{Acknowledgements}

Source of funding: The study was funded by the Center for Livable Future, Johns Hopkins University and the US Department of Agriculture/Food Assistance and Nutrition Research Program. Conflict of interest declaration: None declared. Authorship contributions: H.-J.S., the first author of this paper, conducted all data analysis and was involved in all aspects of its development and implementation. As principal investigator of the Baltimore Healthy Stores study, J.G. first conceived of the study, aided in the development of instruments and provided significant suggestions and comments on the manuscript. As a renowned researcher in community-based participatory research, M.K. provided pivotal information and suggestions related to Korean-American merchants. S. Suratkar assisted in the programme implementation. J.A. and S. Sharma are experts in nutrition and made substantial inputs to improve the paper. All authors helped to revise the paper, interpret findings and reviewed drafts of the manuscript.

\section{References}

1. US Department of Health and Human Services (2001) The Surgeon General's Call to Action to Prevent and Decrease Overweight and Obesity. Rockville, MD: DHHS.

2. Cummins S \& Macintyre S (2006) Food environments and obesity - neighbourhood or nation? Int J Epidemiol 35, 100-104.

3. Egger G \& Swinburn B (1997) An ecological approach to the obesity pandemic. BMJ 315, 477-480.

4. Drewnowski A (2004) Obesity and the food environment: dietary energy density and diet costs. Am J Prev Med 27, 154-162.
5. Booth K, Pinkston M \& Poston W (2005) Obesity and the built environment. J Am Diet Assoc 105, Suppl., S110-S117.

6. Arfken CL \& Houston CA (1996) Obesity in inner-city African Americans. Ethn Health 1, 317-326.

7. Brown M (1999) Supermarket blackout: there are few supermarkets in cities, meaning that blacks pay more for food, lose out on jobs, and go elsewhere for quality foods. Black Enterprise 29, issue 12, 81-92.

8. Alwitt L (1997) Retail stores in poor urban neighborhood. J Consum Aff 31, 139-164.

9. Bolen E \& Hecht K (2003) Neighborhood Groceries: New Access to Healthy Food in Low-Income Communities. San Francisco, CA: California Food Policy Advocates.

10. Fitzgibbon ML \& Stolley MR (2004) Environmental changes may be needed for prevention of overweight in minority children. Pediatr Ann 33, 45-49.

11. Klein A (2002) Baltimoreans are hungry for supermarkets; Groceries: City officials coax chains to open more stores, as residents pay dearly for food at corner shops and drugstores. The Sun, Baltimore, MD, 21 May.

12. Glanz K, Sallis J, Saelens B \& Frank L (2005) Healthy nutrition environments: concepts and measures. $\mathrm{Am} \mathrm{J}$ Health Promot 19, 330-333.

13. Wrigley N, Warm D, Margetts B \& Whelan A (2002) Assessing the impact of improved retail access on diet in a 'food desert': a preliminary report. Urban Stud 39, 2061-2082.

14. Glanz K \& Hoelscher D (2004) Increasing fruit and vegetable intake by changing environments, policy and pricing: restaurant-based research, strategies and recommendations. Prev Med 39, Suppl. 2, S88-S93.

15. Reger B, Wootan M \& Booth-Butterfield S (1999) Using mass media to promote healthy eating: a community-based demonstrating project. Prev Med 29, 414-421.

16. Gittelsohn J, Franceschini M, Rasooly I, Ries AV, Ho LS, Pavlovich W, Santos VT, Jennings S \& Frick KD (2009) Understanding the food environment in a low income urban setting: implications for food store interventions. J Hunger Environ Nutr (In the Press).

17. Seymour JD, Yaroch AL, Serdula M, Blanck HM \& Khan LK (2004) Impact of nutrition environmental interventions on point-of-purchase behavior in adults: a review. Prev Med 39, Suppl. 2, S108-S136.

18. Short A, Guthman J \& Raskin S (2007) Food deserts, oases, or mirages?: small markets and community food security in the San Francisco Bay area. J Plan Educ Res 26, 352-364.

19. Harris NK (2005) Assessment of new approaches to food security in West Oakland. http://66.102.1.104/scholar?hl= ko\&lr $=\& q=$ cache:UdmNPTwW28QJ:ist-socrates.berkeley. edu/ es196/projects/2005final/Harris.pdf + related:Udm NPTwW28QJ:scholar.google.com/ (accessed February 2009).

20. Maryland Advisory Committee to the US Commission on Civil Rights (2004) City Services and the Justice System: Do Korean American Storeowners in Baltimore, Maryland Get Equal Treatment? http://www.law.umaryland.edu/marshall/ usccr/documents/cr122004024429.pdf (accessed February 2009).

21. Sharma S, Cao X, Gittelsohn J, Arcan H, Mattingly M, Jennings S, Song H-J \& Caballero B (2009) Assessing dietary intake for the development of a Quantitative Food Frequency Questionnaire (QFFS) to develop a nutrition intervention to reduce risk of chronic diseases in an inner city African American population. Int J Food Sci Nutr (In the Press).

22. Gittelsohn J, Suratkar S, Song HJ, Sacher S, Rajan R, Rasooly I, Bednarek E \& Sharma S (2009) Process evaluation of Baltimore Healthy Stores: a pilot health intervention program with supermarkets and corner stores in Baltimore 
City. Health Prom Pract (Epublication ahead of print version).

23. Cheadle A, Psaty B, Curry S, Wagner E, Diehr P \& Koepsell $\mathrm{T}$ (1991) Community-level comparisons between the grocery store environment and individual dietary practices. Prev Med 20, 250-261.

24. Kristal A, Goldenhar L, Muldoon J \& Morton R (1997) Evaluation of a supermarket intervention to increase consumption of fruits and vegetables. Am J Health Promot 11 $422-425$.
25. Levy A, Schucker R, Tenney J \& Mathews O (1985) The impact of a nutrition information program on food purchases. J Public Policy Mark issue 4, 1-16.

26. Rogers A, Kessler L, Portnoy B, Potosky A, Patterson B \& Tensema E (1994) Eat for Health: a supermarket intervention for nutrition and cancer risk reduction. Am J Public Health 84, 72-76.

27. Skerratt S (1999) Food availability and choice in rural Scotland: the impact of 'place'. $B r$ Food $J$ 101, 537-544. 